\title{
The Sublime Figure of History
}

Aesthetics and Politics in

Twentieth-Century China 



\section{The Sublime Figure of History}

Aesthetics and Politics in

Twentieth-Century China

Ban Wang

Stanford University Press

Stanford, California 
Stanford University Press

Stanford, California

(C) 1997 by the Board of Trustees of the

Leland Stanford Junior University

Printed in the United States of America

CIP data appear at the end of the book 
To Xiaoyan and Emily 
